\title{
Sequential graft-interpenetrating polymer networks based on polyurethane and acrylic/ester copolymers
}

\author{
R. Ballestero ${ }^{1}$, B. M. Sundaram ${ }^{2}$, H. V. Tippur ${ }^{2}$, M. L. Auad ${ }^{1}$ \\ ${ }^{1}$ Deparment of Chemical Engineering, Auburn University, 36849 Auburn, United States \\ ${ }^{2}$ Deparment of Mechanical Engineering, Auburn University, 36849 Auburn, United States
}

Received 22 June 2015; accepted in revised form 4 October 2015

\begin{abstract}
Highly transparent and tough graft-interpenetrating polymer networks (graft-IPNs) were synthesized using an elastomeric polyurethane phase (PU) and a highly stiff acrylate-base copolymer phase. The grafting points between the two networks were generated with the purpose of minimizing the phase separation process of the polymeric systems. In order to generate the grafting between the networks, an acrylic resin capable of undergoing both free radical and poly-addition polymerization was employed. The thermo-mechanical properties, fracture toughness properties as well as network and surface phase morphology of the graft-IPNs synthesized were evaluated in this work. Data obtained suggested that the minimization of the phase separation was achieved by the generation of crosslinking points between both networks. High transparency was obtained in all samples as an indication of the high level of interpenetration achieved. The relative high values obtained for the fracture toughness tests suggest that generating chemical crosslinks between networks is a good approach for increasing the fracture toughness of polymeric materials.
\end{abstract}

Keywords: thermal properties, graft-IPNs, fracture toughness, BisGMA, sequential polymerization

\section{Introduction}

Over the past decades, polymer blends also known as multiphase polymeric systems have been employed in a broad number of design applications that require high resistance to fracture, a highly desired characteristic for virtually all engineering materials [1]. These polymeric materials became appealing due to their low density when compared with other engineering materials, due to the ability to synergistically incorporate properties of their individual components and achieve materials with better mechanical properties than the original constituents, as well as for their transparency [2]. The challenges with these multiphase systems are to improve their compatibility and interfacial adhesion between phases, so as to guarantee the desired performance of the final material. It is known that only a relatively small number of polymer pairs form miscible blends, mostly because of these blends have low entropy of mixing. Although the entropy of mixing favors the miscibility of a given system, it also depends on the number of molecules per unit volume. Thus, the higher the molecular weight of the polymers involved, the fewer molecules per unit volume and the lower the entropy of mixing. And since the heat of mixing of polymers pairs is generally unfavorable, polymer blends tend to macroscopically phase separate, leading to systems with poor mechanical properties [3-5]. In order to overcome this problem, many efforts have been made to find different ways to improve the miscibility of multiphase systems, one of this approaches involves the use of interfacial agents. These agents decrease the average domain size of the disperse phase by acting as steric barriers at the interphase

\footnotetext{
*Corresponding author, e-mail: auad@auburn.edu

(C) BME-PT
} 
region, enhancing the level of interactions between the polymer phases [6-8].

Another well-known method to minimize phase separation in a polymeric system is through interpenetrating polymer networks (IPNs). Mignard et al. [5] define an interpenetrating polymer network as a system constituted by two or more polymer networks partially interlaced on a polymeric scale but not chemically crosslinked. Different kinds of IPNs can be found based on the synthesis method; the two most common methods for their synthesis are sequential and simultaneous polymerization [5]. In the synthesis of IPNs, at least one of the polymers in the system is in the form of a monomer, and since most monomers are small molecules they have appreciable entropy of mixing. Also, the presence of physical interlocks give to the IPNs a more uniform phase structure than those of the parent polymer blends, leading to what is called forced miscibility, since the compatibility is not achieved by the mixing enthalpy or entropy [5, 9]. Nevertheless, IPNs usually present some degree of phase separation at some stage of the synthesis. For instance, it has been observed that synthesis of IPNs by simultaneous method results in phase separation [10]. Phase separation in sequential polymerization has also been observed, here, the entropy of mixing is lost during the second polymerization, due to the increase in size of the molecules as the polymerization continues [4]. In early works done by Chen et al. [11] and Fan et al. [12] they reported the implementation of a vinyl ester resin (VE) with a polyurethane network for the synthesis of simultaneous interpenetrating polymer networks. This VE resin was capable of undergoing both free radical polymerization as well as stepwise polymerization. Here the formation of crosslinks between networks was never the objective.
Furthermore, the generation of crosslinks was in fact avoided. Studies on the morphology showed clearly that more than one phase was present in the system, as a result of the phase separation between networks.

In the present work, we addressed the phase separation problem of IPNs by generating chemical crosslink points between two networks, thus, generating a class of IPNs called graft-IPNs as seen in Figure 1a. The graft-IPNs synthesized in this work consisted of a highly stiff copolymer phase, which comprises bisphenol A bis(2-hydroxy-3-methacryloxypropyl) ether (BisGMA) resin and two acrylic monomers: methyl methacrylate (MMA) and triethylene glycol dimethacrylate (TEDGMA), and a soft, rubbery polyurethane phase (PU) with a high capability of energy absorption. The crosslinking of the two networks is accomplished by means of the BisGMA resin. This resin has terminal double bonds and secondary hydroxyl groups, which allows the resin to react with the acrylic monomers by radical polymerization, as well as undergo a polyaddition between the secondary $(-\mathrm{OH})$ groups and the $(\mathrm{NCO})$ groups of the isocyanate [13-15], as seen in Figure $1 b$.

The synthesis of graft-IPNs was carried out using the sequential methodology, where the PU phase was polymerized first. Then the copolymer, which was swelling the elastomeric phase, was polymerized in situ within the PU network. The thermomechanical properties, fracture properties as well as the phase morphology of the graft-IPNs were studied in this work.

\section{Experimental \\ 2.1. Materials}

For the synthesis of the polyurethane phase (PU), two polyols were employed: 2-ethyl-2-(hydroxymethyl)-

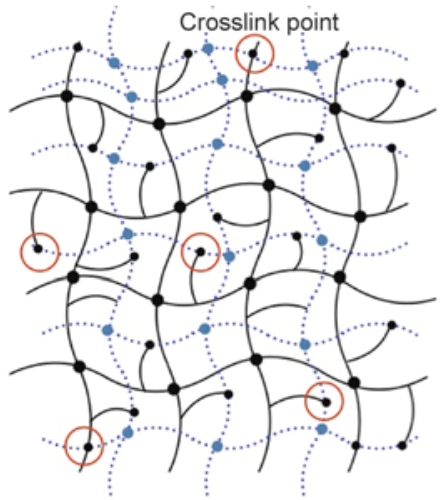

a)

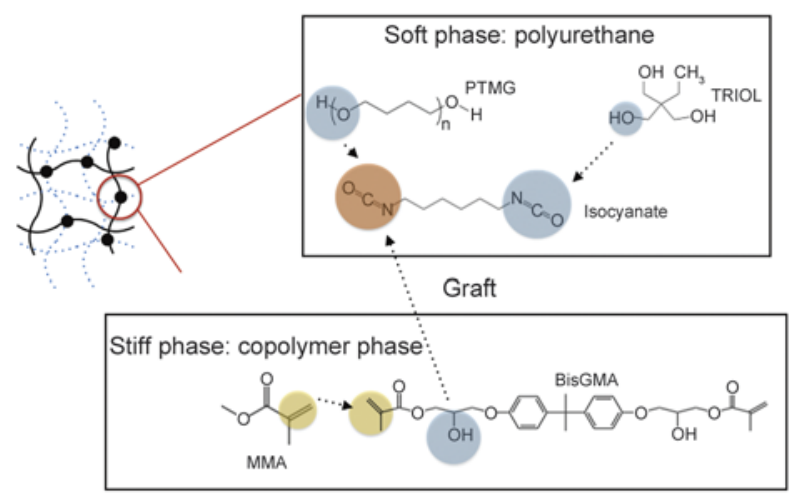

b)

Figure 1. a) Scheme of a graft-IPN, b) scheme of graft formation 
1,3propanediol (TRIOL) from Acros Organics, (USA) and poly(tetramethylene ether) glycol (PTMG) average $M_{\mathrm{n}} \sim 650$ and $\sim 1400 \mathrm{~g} \cdot \mathrm{mol}^{-1}$ from SigmaAldrich, (USA). Both TRIOL and PTMG were mixed beforehand, through melting. The TRIOL and PTMG mixture was melted in an oven under strong vacuum to remove moisture. This procedure was employed for the different molecular weight PTMGs. The isocyanate used was hexamethylene diisocyanate $98.0 \%(\mathrm{DCH})$ from TCI, (USA). Two catalysts were used for the synthesis: dibutylin dilaurate, 98\% (DD) distributed by Pfaltz and Bauer, (USA) and triphenylbismuth, 99+\% (TB) from Alfa Aesar, (USA). Ethyl acetate was used as an analogue for both catalysts.

The copolymer was synthetized using the bisphenol A bis(2-hydroxy-3-methacryloxypropyl) ether (BisGMA) from Esstech, (USA) and two acrylic monomers: methyl methacrylate 99\% stabilized (MMA) from Alfa Aesar, (USA) or triethylene glycol dimethacrylate stabilized (TEGDMA) from TCI, (USA) (see Structure 1) while 2,2'-azobis(2-methylpropionitrile), 98\% (AIBN) from Sigma-Aldrich, (USA) was used as an initiator.

\subsection{Synthesis of graft-IPNs}

The synthesis of the different graft-IPN systems was carried out in a single-step procedure. Both the copolymer phase and the PU phase were prepared separately at room temperature conditions.

First, the copolymer was prepared by mixing the acrylic monomer (MMA or TEGDMA) with the BisGMA resin, keeping a mass ratio of 90:10 acrylate:BisGMA. The amount of radical initiator employed for the polymerization was $1 \mathrm{wt} \%$ of the total copolymer mass. For the polyurethane phase, the DCH was added to the PTMG/TRIOL mixture. The following ratio was used to synthesize all polyurethane networks, 0.19 eq TRIOL:0.12 eq PTMG: $0.31 \mathrm{eq} \mathrm{DCH}$. In order to generate the crosslink points between networks, an additional quantity of DCH was added to the polyurethane precursor solution in a eq ration of 1:1 DCH:BisGMA. Then, the polyurethane precursors were added to the copolymer precursor solution. Following this, DD and TB were added to catalyze the polyurethane system. After mixing both solutions, all samples were placed in an oven at $40^{\circ} \mathrm{C}$ for $17 \mathrm{~h}$ after which the samples were transferred to a water bath where the temperature was raised to $60^{\circ} \mathrm{C}$ for $24 \mathrm{~h}$ and finally the temperature was raised to $80^{\circ} \mathrm{C}$ for $24 \mathrm{~h}$.

Several graft-IPN formulations were prepared following the above-mentioned procedure. The ratio of copolymer to polyurethane content changed from $90 \mathrm{wt} \%$ copolymer and $10 \mathrm{wt} \%$ PU to $50 \mathrm{wt} \%$ copolymer and $50 \mathrm{wt} \% \mathrm{PU}$, this was reproduced for the 650 and $1400 \mathrm{~g} \cdot \mathrm{mol}^{-1}$ PTMG methyl methacrylate based graft-IPNs, as well as for the $650 \mathrm{~g} \cdot \mathrm{mol}^{-1}$ PTMG triethylene glycol dimethacrylate based graft-IPNs.

\subsection{Characterization of graft-IPNs}

Fourier transform infrared spectroscopy (FT-IR) was done using a Thermo Scientific Nicolet ${ }^{\mathrm{TM}} 6700$ spectrometer in attenuated total reflection (ATR) infrared mode. The analysis was carried out within the frequency range of $4000-400 \mathrm{~cm}^{-1}$ by co-adding 32 scans and at a resolution of $2 \mathrm{~cm}^{-1}$.

Dynamic mechanical analysis (DMA) on a TA Instruments RSA III was carried out to assess the thermomechanical properties by three-point bending. The tests were performed at temperatures ranging from 45 to $200^{\circ} \mathrm{C}$ with a heating rate of $5^{\circ} \mathrm{C} / \mathrm{min}$. The frequency was fixed a $1 \mathrm{~Hz}$ and a sinusoidal strainamplitude of $0.1 \%$ was used for the analysis. The dynamic storage modulus $\left(E^{\prime}\right)$ and $\tan \delta$ curves were plotted as a function of temperature. The temperature at the maximum in the $\tan \delta$ curve was taken as the $T_{\mathrm{g}}$. The $E^{\prime}$ at $T_{\mathrm{g}}+50^{\circ} \mathrm{C}$ was chosen as the rubbery plateau modulus, $E_{\mathrm{R}}$, for each system.

The average molecular weight between crosslinks $\left(M_{\mathrm{C}}\right)$ for the 650 and $1400 \mathrm{~g} \cdot \mathrm{mol}^{-1}$ PU based systems was calculated using Equation (1), which is based on the theory of rubber elasticity [16]:

$M_{\mathrm{C}}=\frac{3 \rho R T}{E_{\mathrm{R}}}$

where $\rho$ is the density of the sample; $T$ is the temperature $[\mathrm{K}] ; R$ is the universal gas constant, and $E_{\mathrm{R}}$ is the storage modulus in the rubbery plateau at temperature $T$.

Transmission electron microscopy (TEM) on a Zeiss EM 10C 10CR microscope was used to study the morphology of the different networks. Samples were prepared using Kato's osmium tetroxide $\left(\mathrm{OsO}_{4}\right)$ staining method, as described elsewhere 
[17]. All samples were stained for 48 hours prior to analysis.

UV- Vis transmittance spectra were collected for the various ratios of MMA based copolymer to 650 and $1400 \mathrm{~g} \cdot \mathrm{mol}^{-1}$ PTMG based polyurethane. A UV-Vis 2450 spectrophotometer from Shimadzu Scientific Instruments was employed to acquire the spectra data. All samples were analyzed in the 900$400 \mathrm{~nm}$ range.

Scanning electron microscopy (SEM) on a Zeiss EVO 50 variable pressure scanning electron microscope with digital imaging and EDS (were the graftIPNs were sputter coated with an EMS 550X auto sputter coating device with carbon coating attachment) was used to study the fracture surfaces of the $1400 \mathrm{~g} \cdot \mathrm{mol}^{-1}$ PTMG based system.

In order to characterize the fracture toughness of the graft-IPNs synthesized, in terms of the critical stress intensity factor, KIC, quasi-static fracture tests were performed. The cured graft-IPN sheets were machined into rectangular coupons of dimensions $70 \mathrm{~mm} \times 20 \mathrm{~mm}$ and $2.8 \mathrm{~mm}$ thickness in case of $650 \mathrm{~g} \cdot \mathrm{mol}^{-1}$ PTMG methyl methacrylate based graftIPNs and $70 \mathrm{~mm} \times 15 \mathrm{~mm}$ and $2.8 \mathrm{~mm}$ thickness for $1400 \mathrm{~g} \cdot \mathrm{mol}^{-1}$ PTMG methyl methacrylate based graft-IPNs. An edge notch of $3 \mathrm{~mm}$ in length was cut into the samples, and the notch tip was sharpened using a razor blade. An Instron 4465 universal testing machine was used for loading the specimen in tension and in displacement control mode (crosshead speed $=1 \mathrm{~mm} / \mathrm{min}$ ). The load-deflection data was recorded up to crack initiation and during stable crack growth, if any. The crack initiation toughness or critical stress intensity factor, $K_{\mathrm{IC}}$, was calculated using the load $(F)$ recorded at crack initiation. For each graft-IPN category, at least three sets of experiments were performed at laboratory conditions. The mode-I stress intensity factor for a single edge notched (SEN) tensile strip using linear elastic fracture mechanics is given by Equation (2) [18]:

$K_{\mathrm{Ic}}=\frac{F \sqrt{\pi a}}{B w} f\left(\frac{a}{w}\right)$

where $f(a / w)$ is calculated from Equation (3): where $a$ is the edge crack length, $w$ is the specimen width, $B$ is the specimen thickness and $F$ is the peak load.

To characterize the tensile properties of graft-IPNs in terms of the elastic modulus, yield and ultimate stresses, quasi-static tension tests were performed. For quasi-static tension tests, the cured graft-IPN sheets were machined into dumbbell shaped specimen, which was inspired by ASTM D638 test method [19]. The size of the sheets that could be prepared precluded a complete adherence to ASTM standards. An Instron 4465 universal testing machine was used for loading the specimen in tension and in displacement control mode (crosshead speed $=1 \mathrm{~mm} / \mathrm{min}$ ). An extensometer with 0.25 " gauge length was used to record the strain. The load vs strain data was recorded up to $7 \%$ strain for $650 \mathrm{~g} \cdot \mathrm{mol}^{-1} \mathrm{PTMG}$ methyl methacrylate based graft-IPNs and up to $20 \%$ strain for $1400 \mathrm{~g} \cdot \mathrm{mol}^{-1}$ PTMG methyl methacrylate based graft-IPNs. Using the geometry of the specimen, stress was evaluated from load measurements to obtain stress vs strain data. For each graft-IPN category, at least three sets of experiments were performed at laboratory conditions. The elastic modulus was evaluated from the slope of the stress-strain curve at less than $2 \%$ strain.

Scanning electron microscopy (SEM) on a Zeiss EVO 50 variable pressure scanning electron microscope with digital imaging and EDS (were the graftIPNs were sputter coated with an EMS 550X auto sputter coating device with carbon coating attachment) was used to study the fracture surfaces of the $1400 \mathrm{~g} \cdot \mathrm{mol}^{-1}$ PTMG based system.

\section{Results and discussion}

\subsection{Analysis of FTIR measurements}

In order to monitor the polymerization process of the polyurethane network infrared spectra were recorded. The analysis if based on the peak change of the functional group isocyanate (NCO) and acrylic double bond during the reaction time. The isocyanate absorption band is assigned at approximately 2300 $2200 \mathrm{~cm}^{-1}$ in the mid infrared spectrum and its decay can be used to follow the conversion of the $\mathrm{NCO}$

$$
f\left(\frac{a}{w}\right)=\left[1.12-0.23\left(\frac{a}{w}\right)+10.6\left(\frac{a}{w}\right)^{2}-21.7\left(\frac{a}{w}\right)^{3}+30.4\left(\frac{a}{w}\right)^{4}\right]
$$


group during the polymerization. For scaling the decrease of the NCO absorbance, the $\mathrm{C}-\mathrm{H}$ stretch absorption (approx. $2960 \mathrm{~cm}^{-1}$ ) was used as an internal standard as shown in Figure 2a, since its concentration does not change during the reaction. For the analysis it was assumed that there are no side reactions, and the isocyanate conversion was calculated as shown by Equation (4) [20]:

Isocyanate conversion $p=1-\frac{\frac{A_{\mathrm{NCO}}}{A_{\mathrm{CH}_{2}}}}{\left(\frac{A_{\mathrm{NCO}}}{A_{\mathrm{CH}_{2}}}\right)_{0}}$

where $A_{\mathrm{NCO}}$ is the integrated absorbance for the isocyanate group, $A_{\mathrm{CH}_{2}}$ is the integrated absorbance for the $\mathrm{CH}_{2}$ group and $\left(A_{\mathrm{NCO}} / \mathrm{ACH}_{2}\right)_{0}$ is the relative absorbance extrapolated for time zero. All experiments were carried out at temperatures and times use for the synthesis of graft-IPNs. Figure $2 b$ shows the results from the FTIR experiments and the corresponding NCO conversion curves. The samples analyzed

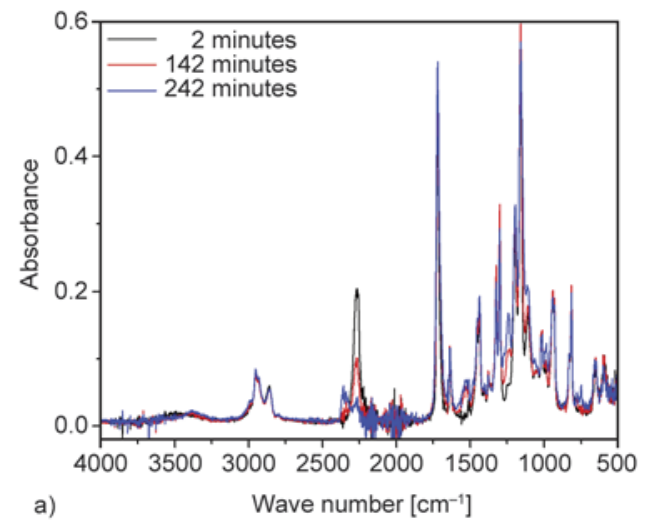

by infrared spectroscopy were: 70:30 copolymer:PU graft-IPN, pure PU, PU+BisGMA and DCH+BisGMA. All samples were synthesized using the $650 \mathrm{~g} \cdot \mathrm{mol}^{-1}$ PTMG. From Figure $2 \mathrm{~b}$ it can be seen that the PU network and the graft-IPN reached very similar conversion values after 3900 minutes of reaction. One can also notice that the conversion value for the NCO on the graft-IPN sample was close to $93 \%$. For this sample in particular a NCO conversion above $82 \%$ is an indication of the reaction of the secondary hydroxyl groups present in the BisGMA resin with free NCO groups in the PU network. Since $18 \%$ of the total NCO present in the sample is added with the sole purpose of generating grafts between networks, this means that $62 \%$ of the total possible grafts were generated during the reaction time. Moreover, by analyzing these curves it seems that the presence of the methyl methacrylate monomer does not have a strong influence in the formation of the PU network in the graft-IPN system, since their conversion curves are practically overlapping.

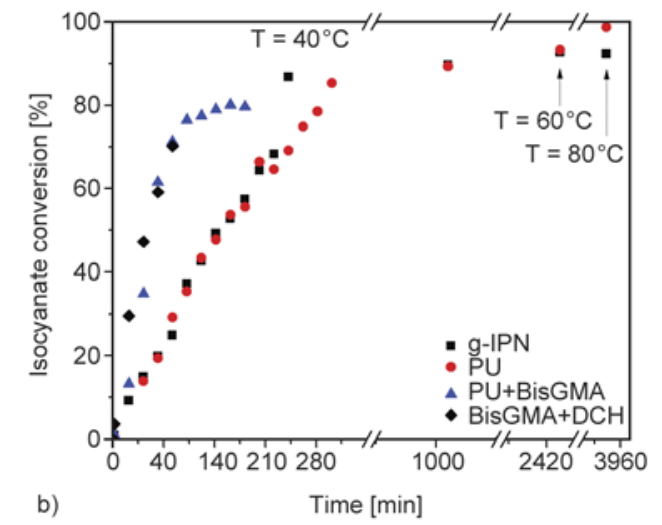

Figure 2. a) FTIR of graft-IPNs at different times during the curing process, b) isocyanate conversion plot

Table 1. Storage modulus $\left(E^{\prime}\right)$, glass transition temperature $\left(T_{\mathrm{g}}\right)$, storage modulus at the rubbery plateau $\left(E_{\mathrm{R}}\right)$ and $M_{\mathrm{C}}$ for the different graft-IPNs synthesized

\begin{tabular}{|c|c|c|c|c|c|}
\hline Sample & $\begin{array}{c}\text { Copolymer content } \\
{[\mathrm{wt} \%]}\end{array}$ & $\begin{array}{c}E^{\prime} \text { at } 25^{\circ} \mathrm{C} \\
{[\mathrm{Pa}]}\end{array}$ & $\begin{array}{c}T_{\mathrm{g}} \\
{\left[{ }^{\circ} \mathbf{C}\right]}\end{array}$ & $\begin{array}{c}E_{\mathrm{R}} \\
{[\mathrm{Pa}]}\end{array}$ & $\begin{array}{c}M_{\mathrm{C}} \\
{\left[\mathrm{g} \cdot \mathrm{mol}^{-1}\right]}\end{array}$ \\
\hline \multirow{5}{*}{ Graft-IPN with $650 \mathrm{~g} \cdot \mathrm{mol}^{-1} \mathrm{PTMG}$} & 90 & $3.35 \cdot 10^{9}$ & 120 & $1.20 \cdot 10^{7}$ & 890 \\
\hline & 80 & $3.02 \cdot 10^{9}$ & 110 & $1.80 \cdot 10^{7}$ & 637 \\
\hline & 70 & $2.07 \cdot 10^{9}$ & 98 & $1.57 \cdot 10^{7}$ & 910 \\
\hline & 60 & $1.40 \cdot 10^{9}$ & 97 & $1.84 \cdot 10^{7}$ & 655 \\
\hline & 50 & $0.96 \cdot 10^{9}$ & 83 & - & - \\
\hline \multirow{5}{*}{ Graft-IPN with $1400 \mathrm{~g} \cdot \mathrm{mol}^{-1}$ PTMG } & 90 & $2.73 \cdot 10^{9}$ & 120 & $1.04 \cdot 10^{7}$ & 1360 \\
\hline & 80 & $2.36 \cdot 10^{9}$ & 107 & $1.36 \cdot 10^{7}$ & 907 \\
\hline & 70 & $1.39 \cdot 10^{9}$ & 97 & $9.77 \cdot 10^{6}$ & 1265 \\
\hline & 60 & $0.95 \cdot 10^{9}$ & 83 & $1.18 \cdot 10^{7}$ & 1030 \\
\hline & 50 & $0.41 \cdot 10^{9}$ & 72 & - & - \\
\hline \multirow{4}{*}{ Graft-IPN with $650 \mathrm{~g} \cdot \mathrm{mol}^{-1}$ PTMG Tri-EDMA } & 90 & $5.28 \cdot 10^{9}$ & 141 & - & - \\
\hline & 80 & $4.41 \cdot 10^{9}$ & 121 & - & - \\
\hline & 70 & $1.08 \cdot 10^{9}$ & 118 & $1.73 \cdot 10^{8}$ & 72 \\
\hline & 60 & $0.62 \cdot 10^{9}$ & 116 & - & - \\
\hline
\end{tabular}


Figure 2a also shows how similar the PU+BisGMA and $\mathrm{DCH}+\mathrm{Bis} G \mathrm{MA}$ conversion curves are. One could speculate that the secondary hydroxyl groups from the BisGMA resin are reacting throughout the entire reaction time and not only when the primary hydroxyl groups coming from the PTMG and TRIOL are depleted. Regarding follow up of the copolymer network formation, the conversion of the acrylic double bonds absorption band in the 1630 $1650 \mathrm{~cm}^{-1}$ was monitored. Although since the data were gathered in the solid state rather than the liquid stated, the data collected was not sufficiently accurate to allow a proper determination of the final double bond conversion of the copolymer network present in the sample. The extent of reaction at the gel point was determined experimentally and theoretically for the samples under analysis. The latter was obtained using Flory and Stockmayer statistical approach to gelation as describe elsewhere [21]. From Table 1 it can be seen that the extent of reaction determined experimentally are really close to the theoretical ones.

\subsection{Thermo-mechanical characterization}

The variables studied in the present work included the ratio of copolymer to $\mathrm{PU}$, the molecular weight of poly (tetramethylene ether) glycol (PTMG) and the acrylic monomer employed to synthesize the copolymer phase. The ratio between the di- to tri-functionalized monomers (PTMG:TRIOL) for the PU phase was kept constant, since it is related to the crosslink density of the PU network. The ratio between the acrylic monomers to BisGMA resin was also kept constant. The number of possible crosslinks between networks is bounded by the reaction of secondary $\mathrm{OH}$

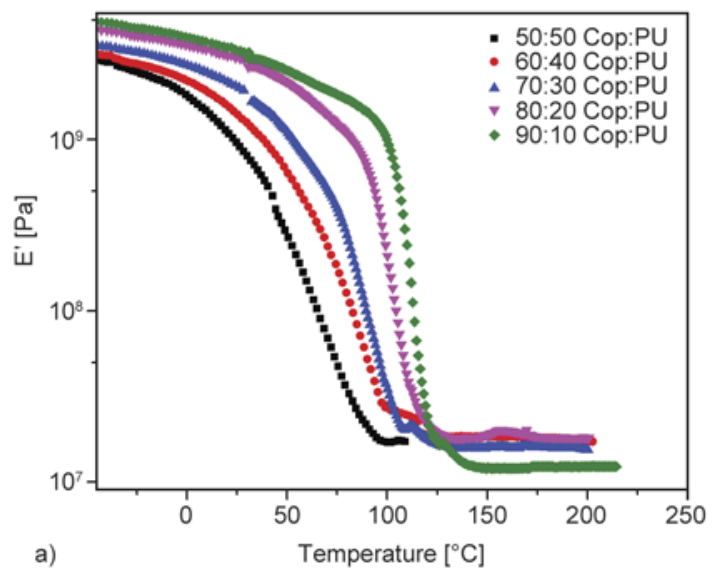

groups present in the BisGMA resin and the free isocyanate groups present in the PU network. If the acrylic monomer to BisGMA ratio were to be changed, the moles of the latter resin would change, thus, altering the number of secondary $\mathrm{OH}$ group available for grafting.

All variables under study showed a major impact on the storage modulus of the systems. However, only the ratio of copolymer to PU and the acrylic monomer used had a significant effect on the $T_{\mathrm{g}}$ of the systems. Figure 3 shows the thermo-mechanical properties (storage modulus, $E^{\prime}$, and $\tan \delta$ ) of the graftIPNs synthesized using the $650 \mathrm{~g} \cdot \mathrm{mol}^{-1}$ PTMG as a function of temperature. In addition, Table 2 summarizes the results for all the different systems studied.

For all systems under study, it was observed that as the copolymer content increased, the samples exhibited higher values for the storage modulus, $E^{\prime}$; a highly expected result since the copolymer phase provides the stiffness to the system. Samples consisting of $90 \mathrm{wt} \%$ copolymer showed a storage modulus of $3.35,2.73 \mathrm{GPa}$ at $25^{\circ} \mathrm{C}$ for the 650 and $1400 \mathrm{~g} \cdot \mathrm{mol}^{-1}$ PTMG methyl methacrylate based graft-IPNs. While for the TEGDMA based graft-IPNs a value of $5.28 \mathrm{GPa}$ at $25^{\circ} \mathrm{C}$ was obtained using the $650 \mathrm{~g} \cdot \mathrm{mol}^{-1}$ PTMG. Samples containing less than $70 \mathrm{wt} \%$ of copolymer showed inferior values for the storage modulus, which can be attributed to the elastomeric contribution of the PU phase. When comparing the systems with different molecular weight PTMGs, a substantial difference in the storage modulus was observed. As shown in Table 2, the storage modulus values for the system using the $1400 \mathrm{~g} \cdot \mathrm{mol}^{-1}$ PTMG are inferior to those of the $650 \mathrm{~g} \cdot \mathrm{mol}^{-1}$. This

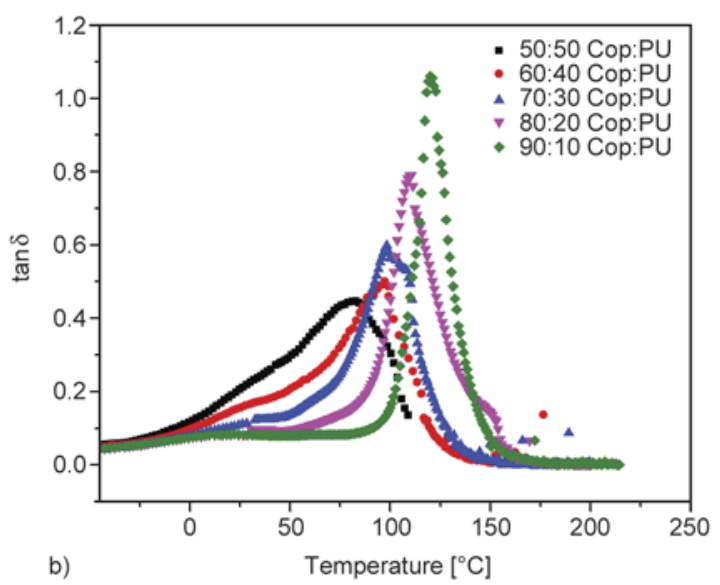

Figure 3. DMA results showing change in (a) $E^{\prime}$ and (b) $\tan \delta$ for graft-IPNs with various ratio of MMA based copolymer to $650 \mathrm{~g} \cdot \mathrm{mol}^{-1} \mathrm{PTMG}$ based polyurethane 
Table 2. Results obtained for the fracture toughness tests performed on different graft-IPNs synthesized

\begin{tabular}{|c|c|c|c|c|c|}
\hline \multirow{2}{*}{ Sample } & $\begin{array}{c}\text { Copolymer content } \\
{[\mathbf{w t} \mathbf{0}]}\end{array}$ & $\begin{array}{c}\boldsymbol{K}_{\mathbf{I c}} \\
{\left[\mathbf{M P a} \cdot \mathbf{m}^{\mathbf{1} / \mathbf{2}}\right]}\end{array}$ & $\begin{array}{c}\boldsymbol{E} \\
{[\mathbf{G P a}]}\end{array}$ & $\begin{array}{c}\text { Ultimate stress } \\
{[\mathbf{M P a}]}\end{array}$ & $\begin{array}{c}\text { Failure strain } \\
{[\%]}\end{array}$ \\
\hline \multirow{3}{*}{ Graft-IPN with 650 $\mathrm{g} \cdot \mathrm{mol}^{-1}$ PTMG } & 90 & $1.17 \pm 0.03$ & $3.3 \pm 0.05$ & 61.79 & 3.05 \\
\cline { 2 - 6 } & 80 & $1.16 \pm 0.14$ & $3.6 \pm 0.03$ & 47.97 & 2.155 \\
\cline { 2 - 6 } & 70 & $2.70 \pm 0.09$ & $2.2 \pm 0.02$ & 35.78 & $>7$ \\
\cline { 2 - 6 } & 60 & $1.84 \pm 0.06$ & $1.3 \pm 0.04$ & 18.06 & $>7$ \\
\cline { 2 - 6 } Graft-IPN with $1400 \mathrm{~g} \cdot \mathrm{mol}^{-1}$ PTMG & 90 & $1.49 \pm 0.05$ & $3.4 \pm 0.05$ & 76.50 & 10.80 \\
\cline { 2 - 6 } & 80 & $2.35 \pm 0.08$ & $2.65 \pm 0.08$ & 52.29 & $>20$ \\
\cline { 2 - 6 } & 70 & $2.95 \pm 0.12$ & $2.5 \pm 0.11$ & 34.27 & $>20$ \\
\hline Graft-IPN with 650 $\mathrm{g} \cdot \mathrm{mol}^{-1}$ PTMG Tri-EDMA & 60 & $1.73 \pm 0.04$ & $1.2 \pm 0.08$ & 18.11 & $>20$ \\
\hline
\end{tabular}

reduction in the storage modulus may be explained by the higher mobility that a longer macrodiol provides to the PU network [10]. When analyzing the storage modulus of the TEGDMA-based samples (see Table 2), it can be seen that the substitution of a single double bond monomer (MMA) in the copolymer for a monomer with two double bonds (TEGDMA) had a major impact on the storage modulus. Samples containing this dimethacrylate monomer had a tendency to present higher storage modulus than those synthesized using MMA. As described by Heatley et al. [22], BisGMA-TEGDMA copolymers are characterized by presenting high degrees of crosslinking, due to presence of two double bonds in their chemical structures, which generated more crosslink points within the copolymer network, resulting in an increase in the crosslink density of the network. This increase in the crosslink density diminished to a certain extent the mobility of the network chains, increasing the stiffness of the system, thus, increasing the storage modulus of the samples. To corroborate this statement, the $M_{\mathrm{C}}$ of the MMA and TEGDMA graft-IPNs were experimentally estimated by measuring the equilibrium storage modulus in the rubbery state, using the Equation (1) from the theory of rubber elasticity. The samples analyzed were the $70 \%$ copolymer content using the $650 \mathrm{~g} \cdot \mathrm{mol}^{-1}$ PTMG. The results showed $M_{\mathrm{C}}$ values of 910 and $72 \mathrm{~g} \cdot \mathrm{mol}^{-1}$ for the MMA and TEGDMA samples respectively. As expected the dimethacrylate-based sample showed the lowest value for $M_{\mathrm{C}}$, which as stated earlier, provides an explanation for the higher values of storage modulus obtained for all TEGDMA-based samples over its MMA-based counterparts.

Figure $3 \mathrm{~b}$, shows the plot of $\tan \delta$ as a function of temperature for the MMA based graft-IPNs synthesized using the $650 \mathrm{~g} \cdot \mathrm{mol}^{-1} \mathrm{PTMG}$. In this graph, a maximum peak of the loss factor showed the char- acteristic relaxation associated with the glass transition temperature of the different systems under study. It was observed that as the weight percentage of copolymer increased in the samples, the maximum peak of the loss factor gained prominence and moved to higher temperatures. The narrow peak of the loss factor in the sample with 80 and $90 \%$ copolymer content suggested a high degree of miscibility. For the rest of the samples a broad transition with a shoulder related to the glass transition of the PU phase was observed in the curves, which it is characteristic of a partially miscible system. A similar peak in the loss factor for the $90 \%$ copolymer content was also observed for the composition using the $1400 \mathrm{~g} \cdot \mathrm{mol}^{-1}$ PTMG, as well as broader transitions for samples containing $<90$ weight percentages of copolymer. This suggests that several different relaxation mechanisms are present in the produced network, and they may be related to the nano-heterogeneity of the system $[10,17]$.

In the case of the TEGDMA-based graft-IPNs, all samples presented broad transitions, also suggesting a high level of heterogeneity in the system. However, in the case of dimethacrylates, the heterogeneity formed, as explained by Podgórsky [23], results from highly crosslinked structures in which a broad distribution of micro-domains can be found. This kind of polymer networks have shown both loosely connectivity and highly crosslinked regions, as well as regions were unreacted monomer is present. This lack of homogeneity in the network structure has as a result the manifestation of a broad distribution of relaxation times due to the matrix mobility.

\subsection{Network morphology}

The network morphology of the graft-IPN was studied to corroborate the improvement achieved in the interpenetration of the two polymer networks as a result of the chemical crosslink between networks. 
Figure 4 shows TEM photos of sections cut from stained methyl methacrylate copolymer based graftIPN samples containing 70\% copolymer content with different molecular weight PTMGs at different stages of the curing process. Here, the dark zones correspond to PU regions, since the PU phase is the one that absorbed the dye, while the clear zones correspond to the copolymer phase.

In general, the morphology presented by different IPNs is rather complex, since different competing processes may occur simultaneously during polymerization. In sequential polymerization; as is the case in this work, the formation of the first network has a major impact on the formation of the second, limiting the range of compositions and the material's final properties obtained by following this synthetic route.

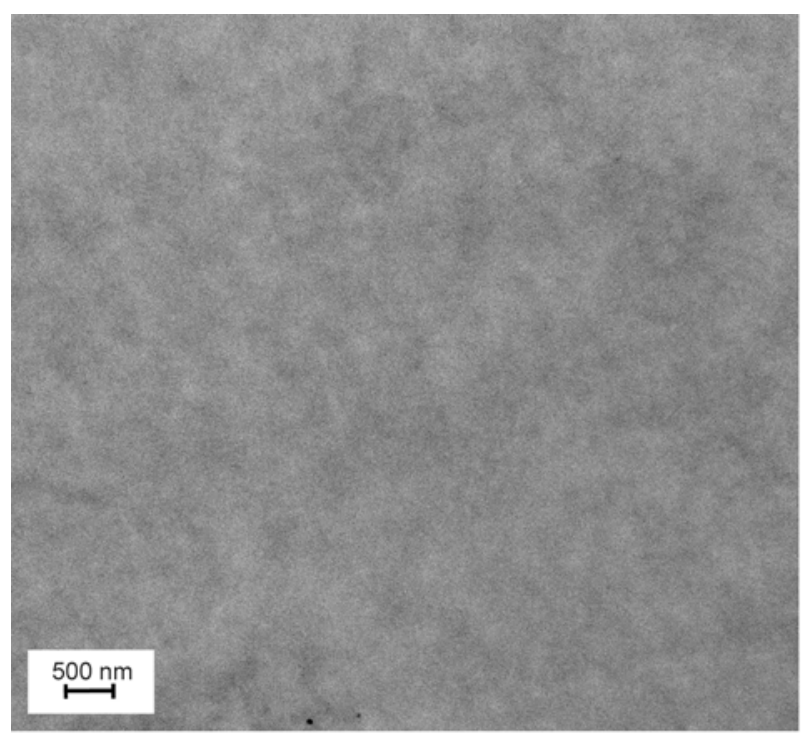

a)

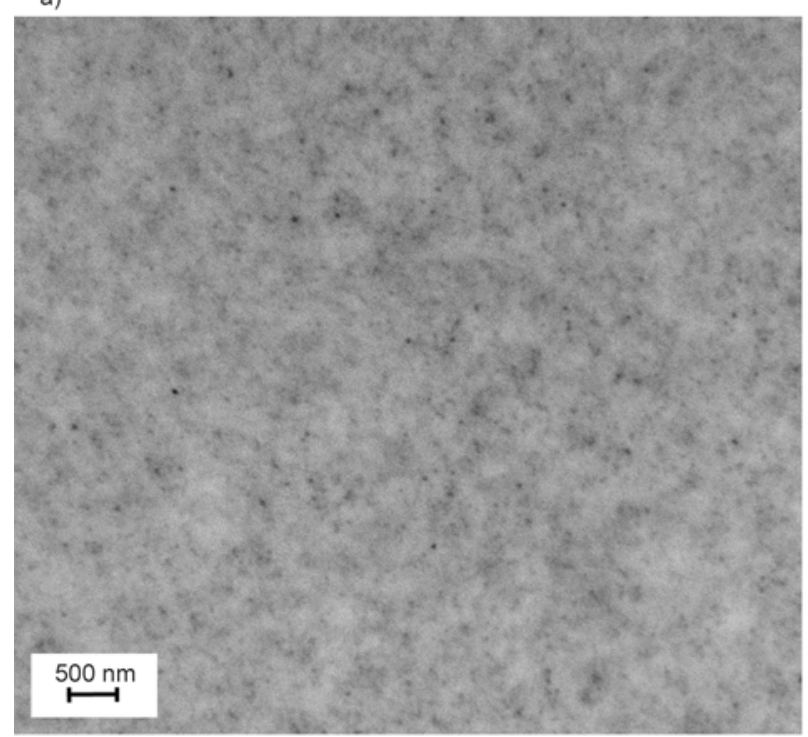

c)
As shown in Figure 4c, it appears to be a slight formation of PU domains for the $1400 \mathrm{~g} \cdot \mathrm{mol}^{-1}$ PTMG graft-IPNs at $60^{\circ} \mathrm{C}$. As the curing process of the samples was finalized after $24 \mathrm{~h}$ at $80^{\circ} \mathrm{C}$, the $\mathrm{PU}$ domains seemed to disappear (see Figure 4d). This observation may be explained by further formation of crosslink points between the two networks by means of the reaction between the hydroxyl groups present in the BisGMA resin with the isocyanate groups present in the PU phase. These TEM pictures are a corroboration of the decrease in size of these domains by the formation of the aforementioned crosslinking points, which improved the system's miscibility, thus minimizing the phase separation between networks [10]. Furthermore, when comparing the two graft-IPNs with different molecular

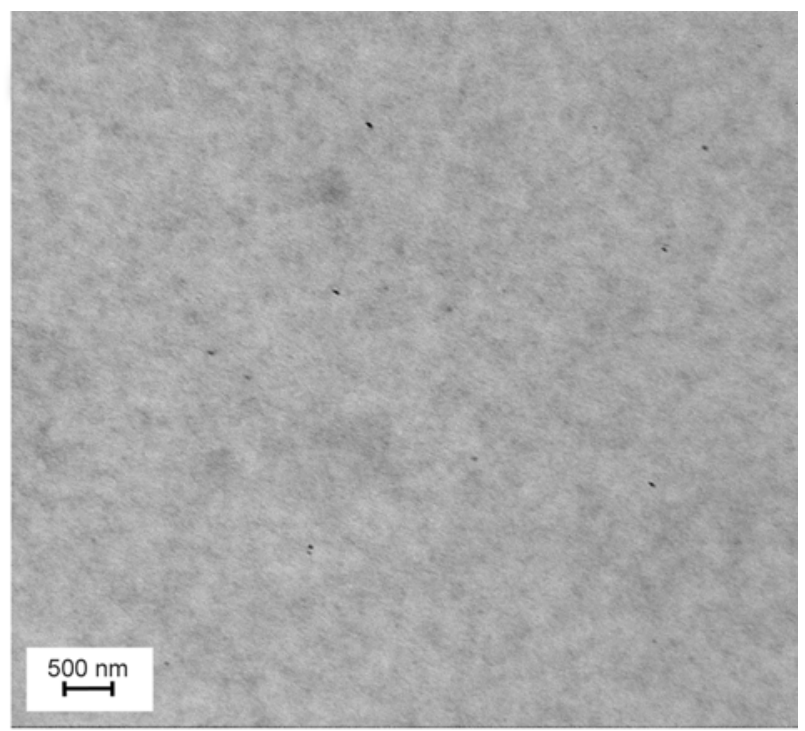

b)

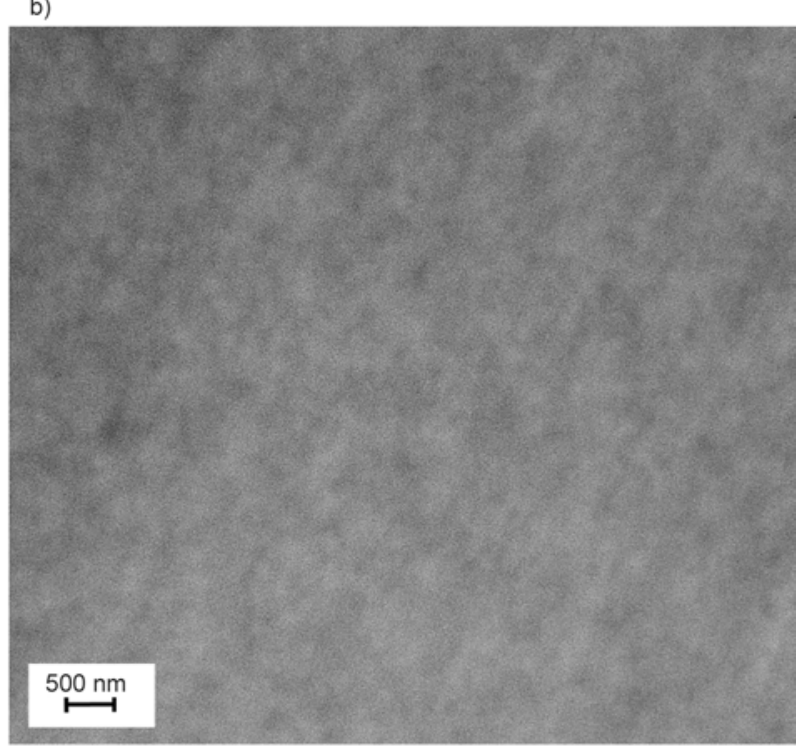

d)

Figure 4. TEM photos of graft-IPNs with $70 \mathrm{wt} \%$ MMA based copolymer using the $650 \mathrm{~g} \cdot \mathrm{mol}^{-1} \mathrm{PTMG}$ at (a) $60^{\circ} \mathrm{C}$, (b) $80^{\circ} \mathrm{C}$ and $1400 \mathrm{~g} \cdot \mathrm{mol}^{-1} \mathrm{PTMG}(\mathrm{c}) 60^{\circ} \mathrm{C}$ and (d) $80^{\circ} \mathrm{C}$ 
weight PTMGs, it can be seen from the TEM pictures that both systems presented a fine dispersion of both networks through the entire sample. This is attributed to the successful interpenetration of the two different networks at the molecular level [17].

\subsection{Degree of transparency}

Transparency of the MMA based copolymer using $650 \mathrm{~g} \cdot \mathrm{mol}^{-1}$ PTMG samples synthesized was analyzed. The system presented a relative high degree of transparency, showing values of transmittance between 65 and 90\%, as shown in Figure 5. The same degree of transparency was also observed for the $1400 \mathrm{~g} \cdot \mathrm{mol}^{-1}$ PTMG based system. These results are also confirmation of the high degree of interpenetration achieved on both systems regardless of the molecular weight of the PTMG. There is no visible evidence of macroscopic phase separation in the samples studied, supporting the results shown in the plot of $\tan \delta$ as a function of temperature.

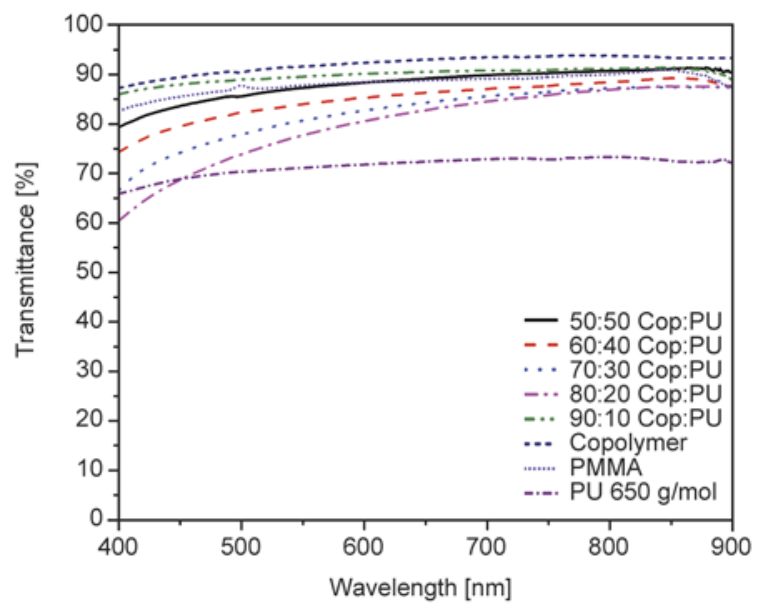

Figure 5. UV-vis spectrum of MMA based copolymer and $650 \mathrm{~g} \cdot \mathrm{mol}^{-1}$ PTMG based PU graft-IPN

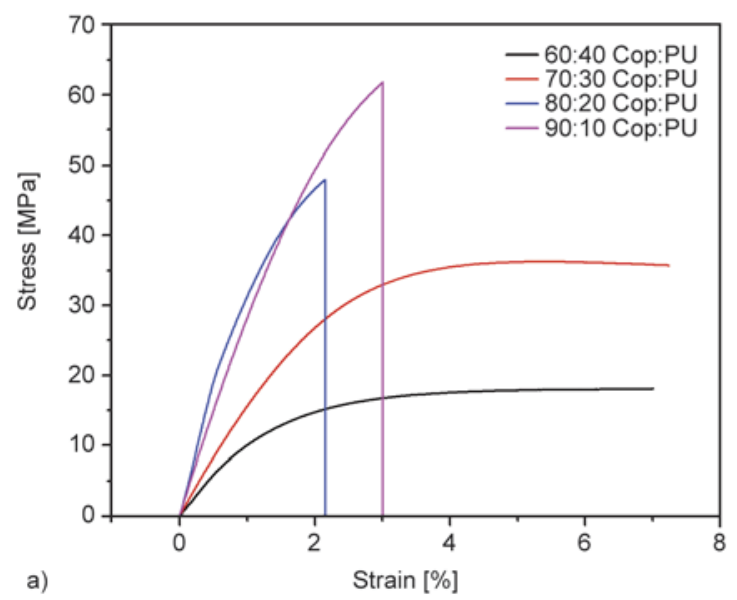

\subsection{Stiffness and fracture toughness}

The stress vs strain plots obtained from the tension tests in case of 650 and $1400 \mathrm{~g} \cdot \mathrm{mol}^{-1}$ PTMG are shown in Figure $6 \mathrm{a}$ and $6 \mathrm{~b}$ respectively. It can be seen that the modulus and the peak stress drops progressively with increase in PU resulting in no observed failure within the window of imposed strains.

Table 3 shows results obtained for the quasi-static crack initiation toughness, $K_{\text {IC }}$ for the graft-IPNs studied. When both systems are compared, it can be seen that the graft-IPNs synthesized with the $1400 \mathrm{~g} \cdot \mathrm{mol}^{-1}$ PTMG have a slightly higher value for the quasistatic crack initiation toughness than those synthesized using the $650 \mathrm{~g} \cdot \mathrm{mol}^{-1}$ PTMG. Furthermore, it can be observed that both systems displayed the highest value of fracture toughness in samples with a $70 \%$ of copolymer content, suggesting that there is an optimum copolymer to PU ratio.

\subsection{Determination of average molecular weight between crosslinks $\left(M_{C}\right)$ and its relation with fracture toughness}

The average molecular weight between crosslinks for the MMA based graft-IPNs was experimentally obtained by measuring the storage modulus in the rubbery plateau, $E_{\mathrm{R}}$, at $50{ }^{\circ} \mathrm{C}$ above the glass transition temperature according to the Equation (1) from

Table 3. Determination of extend of reaction at gel point

\begin{tabular}{|l|c|c|c|}
\hline \multicolumn{1}{|c|}{ Sample } & $\begin{array}{c}\text { Gel time } \\
{[\text { min] }}\end{array}$ & $\begin{array}{c}\text { Conversion at } \\
\text { gel time } \\
\text { (Experimental) }\end{array}$ & $\begin{array}{c}\text { Conversion at gel } \\
\text { time (Flory and } \\
\text { Stockmayer) }\end{array}$ \\
\hline Graft-IPN & 242 & $87 \%$ & $82 \%$ \\
\hline PU & 222 & $69 \%$ & $79 \%$ \\
\hline PU+BisGMA & 182 & $80 \%$ & $82 \%$ \\
\hline DCH+BisGMA & - & - & - \\
\hline
\end{tabular}

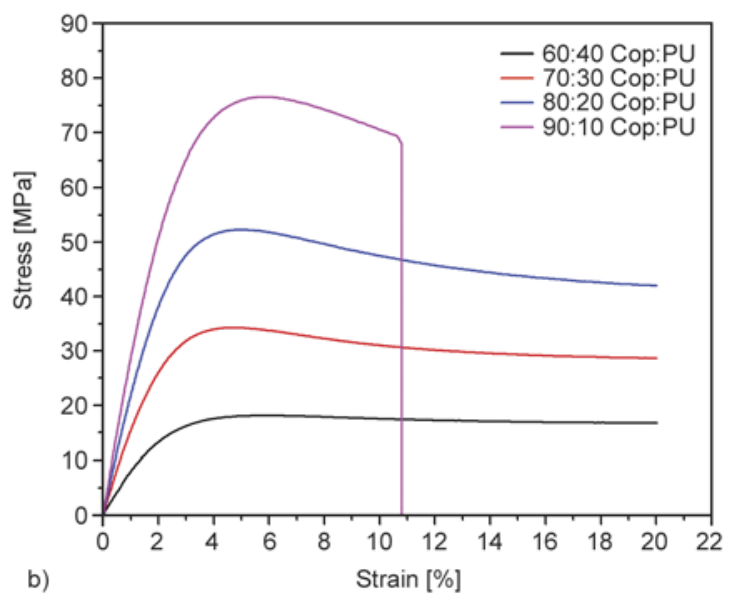

Figure 6. Stress vs. strain plots for MMA based copolymer samples using a) $650 \mathrm{~g} \cdot \mathrm{mol}^{-1} \mathrm{PTMG}$ and b) $1400 \mathrm{~g} \cdot \mathrm{mol}^{-1}$ PTMG based polyurethane during tension test 
the theory of rubber elasticity. In previous studies done by Karger-Kocsis and Gremmels [24], Liang and Pearson [25], Liu et al. [26], a linear correlation between the fracture toughness and $M_{\mathrm{C}}$ was found. It was seen that as $M_{\mathrm{C}}$ increased in the system the higher the $K_{\text {IC }}$ value became. Sherman et al. [27] attribute this to an increase in the free volume of the materials, which allows more space resulting in an increase of chain motions capable to accommodate the applied load. Nevertheless, linear correlation was not found for the system under study, the results showed that the $K_{\mathrm{IC}}$ values did not increase as $M_{\mathrm{C}}$ increased. This tendency holds true for both 650 and $1400 \mathrm{~g} \cdot \mathrm{mol}^{-1}$ PTMG based graft-IPNs.

\subsection{Surface morphology}

In order to study the fracture mechanics of the graftIPN systems, SEM images were taken from samples used for fracture testing. Figure 7 shows the fractured surfaces of graft-IPNs samples with different copolymer to polyurethane ratios for the graft-IPNs synthesized using the $1400 \mathrm{~g} \cdot \mathrm{mol}^{-1}$ PTMG.

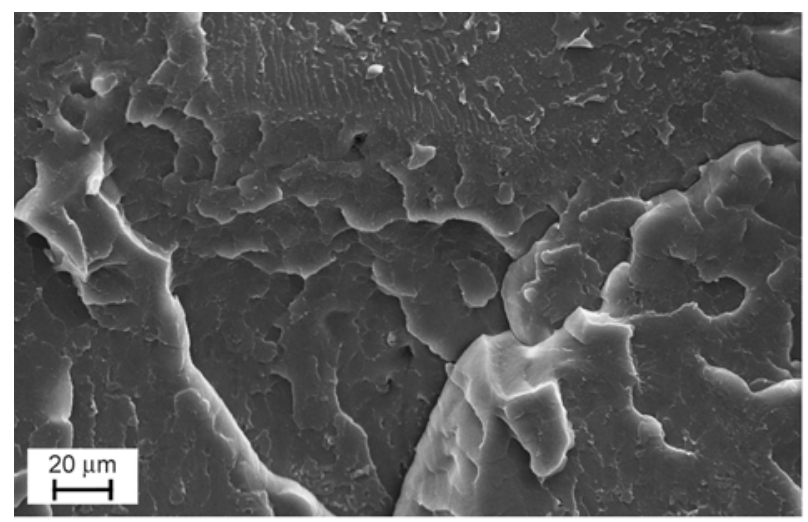

a)

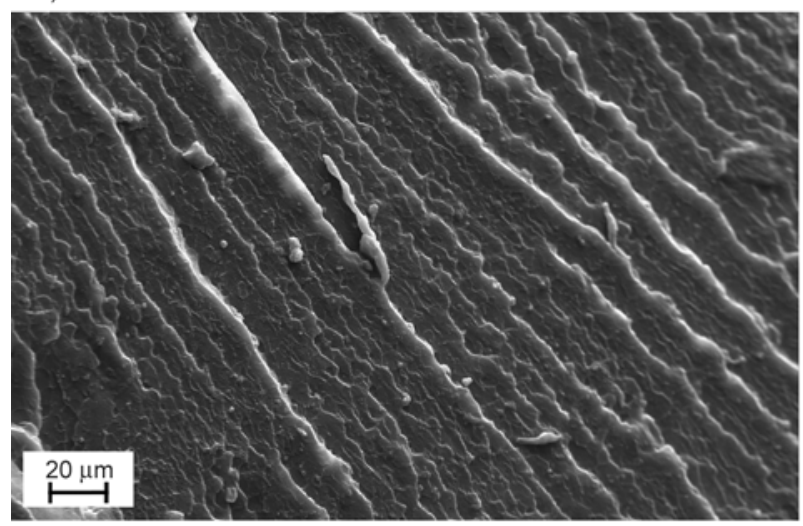

c)
From Figure 7 it can be seen that regardless of PU content present in the samples, this factor does not have a significant effect on the surface area created were the fracture propagated through the material. When compared to previous work done by Bird et al. [17], the authors were able to observe how an increase in the PU content in the system resulted in an increase on the surface area were the fracture propagated through the material. They also observed how the samples with a higher PU content had better fracture toughness values, which led them to correlate the surface area generated during fracture testing with the fracture toughness properties of the material. However, this correlation between an increase of surface area and fracture toughness was not observed on the graft-IPN systems. Although it was possible to see how samples with a copolymer content equal or superior to $80 \%$ show brittle fractures while samples under $80 \%$ copolymer content show did not show a brittle fracture. These results suggest that a different fracture mechanism is responsible for the improvement in the fracture toughness values presented by the graft-IPN.

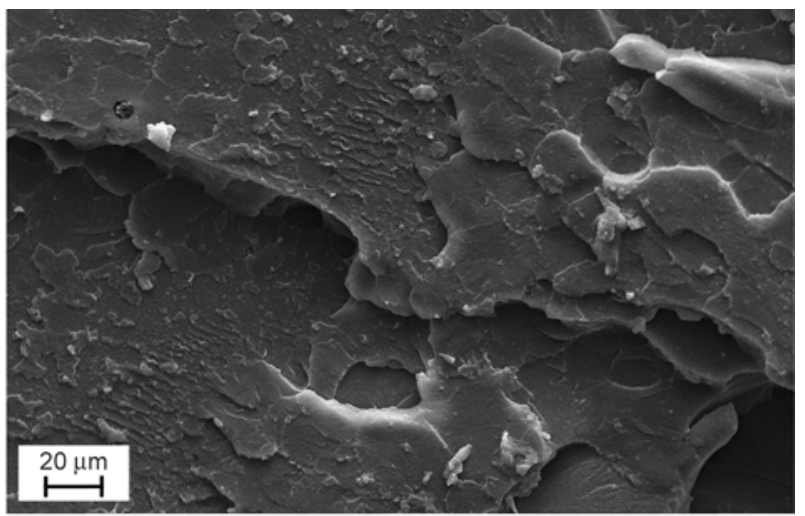

b)

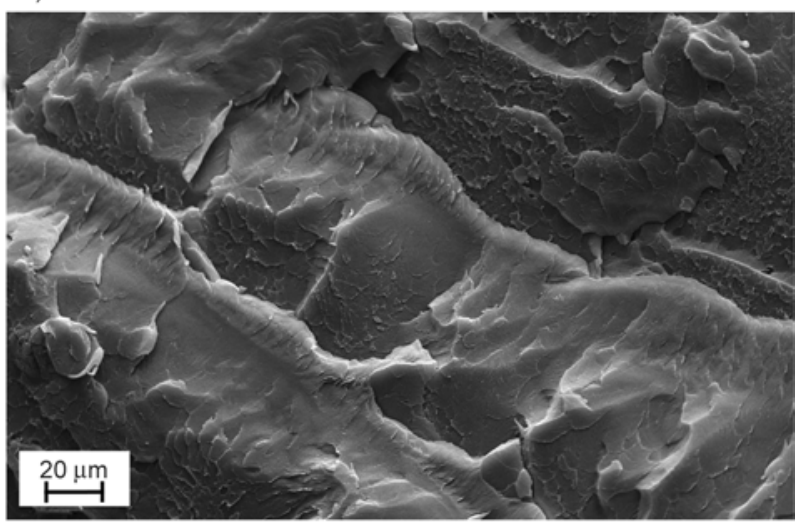

d)

Figure 7. SEM photos of (a) $60 \mathrm{wt} \%$ copolymer, (b) $70 \mathrm{wt} \%$ copolymer, (c) $80 \mathrm{wt} \%$ copolymer and (d) $90 \mathrm{wt} \%$ copolymer MMA-graft-IPN samples using the $1400 \mathrm{~g} \cdot \mathrm{mol}^{-1} \mathrm{PTMG}$ 


\section{Conclusions}

In this study, a series of graft interpenetrated polymer networks consisting of a polyurethane and a copolymer network were synthesized. Where, the influence of the copolymer to PU ratio, molecular weight of the PTMG and copolymer's chemical composition on the thermo-mechanical and fracture toughness properties, as well as both network and surface morphology were systematically studied.

As expected, the findings suggest that the toughenability of the graft-IPNs synthesized was highly dependent on all three aforementioned variables. It was found that samples comprising $70 \mathrm{wt} \% \mathrm{MMA}$ based copolymer and $1400 \mathrm{~g} \cdot \mathrm{mol}^{-1}$ PTMG based polyurethane presented the best combination of high $E^{\prime}, T_{\mathrm{g}}$ and fracture toughness of all systems under study. The network morphology studies showed that there is no clear domains in any of the samples analyzed, what suggests that phase separation was successfully minimized by the generation of crosslink points between the copolymer and PU networks by means of the BisGMA resin. The surface morphology analysis suggests that a different fracture mechanism is accountable for the improvement in the fracture toughness presented by the graft-IPN systems, since there is no clear correlation between an increase on the fracture toughness and an increase in surface area were the fracture propagated in the samples. Additional work is still needed for understanding the fracture mechanism accountable for the high crack initiation toughness showed by graft-IPNs.

\section{Acknowledgements}

We kindly acknowledge the support for this research by the U.S. Army Research Office through grant W911NF-12-10317.

\section{References}

[1] Pfeifer C. S., Silva L. R., Kawano Y., Braga R. R.: BisGMA co-polymerizations: Influence on conversion, flexural properties, fracture toughness and susceptibility to ethanol degradation of experimental composites. Dental Materials, 25, 1136-1141 (2009). DOI: $10.1016 /$ j.dental.2009.03.010

[2] Mulliken A. D., Boyce M. C.: Mechanics of the ratedependent elastic-plastic deformation of glassy polymers from low to high strain rates. International Journal of Solids and Structures, 43, 1331-1356 (2006). DOI: $10.1016 /$ j.ijsolstr.2005.04.016
[3] Panapitiya N. P., Wijenayake S. N., Huang Y., Bushdiecker D., Nguyen D., Ratanawanate C., Kalaw G. J., Gilpin C. J., Musselman I. H., Balkus K. J., Ferraris J. P.: Stabilization of immiscible polymer blends using structure directing metal organic frameworks (MOFs). Polymer, 55, 2028-2034 (2014).

DOI: $10.1016 /$ j.polymer.2014.03.008

[4] Sperling L. H.: Polymeric multicomponent materials: An introduction. Wiley, New York (1997).

[5] Mignard N., Okhay N., Jegat C., Taha M.: Facile elaboration of polymethylmethacrylate/polyurethane interpenetrating networks using Diels-Alder reactions. Journal of Polymer Research, 20, 233/1-233/13 (2013).

DOI: $10.1007 / \mathrm{s} 10965-013-0233-2$

[6] Cerclé C., Favis B. D.: Generalizing interfacial modification in polymer blends. Polymer, 53, 4338-4343 (2012).

DOI: $10.1016 /$ j.polymer.2012.07.027

[7] García-Martínez J. M., Laguna O., Areso S., Collar E. P.: A dynamic-mechanical study of the role of succinil-fluoresceine grafted atactic polypropylene as interfacial modifier in polypropylene/talc composites. Effect of grafting degree. European Polymer Journal, 38, 15831589 (2002).

DOI: 10.1016/S0014-3057(02)00051-4

[8] Wang J-J., Li Z-Z., Gu X-P., Feng L-F., Zhang C-L., Hu G-H.: A dissipative particle dynamics study on the compatibilizing process of immiscible polymer blends with graft copolymers. Polymer, 53, 4448-4454 (2012).

DOI: $10.1016 /$ j.polymer.2012.08.030

[9] Li B. Y., Bi X. P., Zhang D. H., Wang F. S.: Forced compatibility and mutual entanglements in poly(vinyl acetate)/poly(methyl acrylate) IPNs. in 'Advances in interpenetrating polymer networks' (Klempner D., Frisch K. C.) Technomic Pusblishing, Lancaster, Vol 1, 203-219 (1989).

[10] Ramis X., Cadenato A., Morancho J. M., Salla J. M.: Polyurethane-unsaturated polyester interpenetrating polymer networks: Thermal and dynamic mechanical thermal behaviour. Polymer, 42, 9469-9479 (2001).

DOI: 10.1016/S0032-3861(01)00492-X

[11] Chen C-H., Chen W-J., Chen M-H., Li Y-M.: Simultaneous full-interpenetrating polymer networks of blocked polyurethane and vinyl ester Part I. Synthesis, swelling ratio, thermal properties and morphology. Polymer, 41, 7961-7967 (2000). DOI: 10.1016/S0032-3861(00)00173-7

[12] Fan L. H., Hu C. P., Ying S. K.: Thermal analysis during the formation of polyurethane and vinyl ester resin interpenetrating polymer networks. Polymer, 37, 975981 (1996)

DOI: 10.1016/0032-3861(96)87280-6

[13] Gryshchuk O., Jost N., Karger-Kocsis J.: Toughening of vinylester-urethane hybrid resins by functional liquid nitrile rubbers and hyperbranched polymers. Polymer, 43, 4763-4768 (2002). DOI: $10.1016 / \mathrm{S} 0032-3861(02) 00314-2$ 
[14] Jost N., Karger-Kocsis J.: On the curing of a vinylesterurethane hybrid resin. Polymer, 43, 1383-1389 (2002). DOI: 10.1016/S0032-3861(01)00702-9

[15] Karger-Kocsis J., Fröhlich J., Gryshchuk O., Kautz H., Frey H., Mülhaupt R.: Synthesis of reactive hyperbranched and star-like polyethers and their use for toughening of vinylester-urethane hybrid resins. Polymer, 45, 1185-1195 (2004).

DOI: $10.1016 /$ j.polymer.2003.12.050

[16] Cho K., Lee D., Park C.: Effect of molecular weight between crosslinks on fracture behaviour of diallylterephthalate resins. Polymer, 37, 813-817 (1996) DOI: $10.1016 / 0032-3861(96) 87258-2$

[17] Bird S. A., Clary D., Jajam K. C., Tippur H. V., Auad M. L.: Synthesis and characterization of high performance, transparent interpenetrating polymer networks with polyurethane and poly(methyl methacrylate). Polymer Engineering and Science, 53, 716-723 (2013). DOI: $10.1002 /$ pen.23305

[18] Janssen M., Zuidema J., Wanhill R. J. H.: Fracture mechanics. Delft Academic Press/VSSD, Delft (2006).

[19] ASTM D638: Standard test method for tensile properties of plastics (2014).

[20] Cateto C. A., Barreiro M. F., Rodrigues A. E.: Monitoring of lignin-based polyurethane synthesis by FTIRATR. Industrial Crops and Products, 27, 168-174 (2008). DOI: $10.1016 /$ j.indcrop.2007.07.018

[21] Odian G.: Principles of polymerization. Wiley, New York (2004).
[22] Heatley F., Pratsitsilp Y., McHugh N., Watts D. C., Devlin H.: Determination of extent of reaction in dimethacrylate-based dental composites using solidstate ${ }^{13} \mathrm{C}$ m.a.s. n.m.r. spectroscopy and comparison with FTi.r. spectroscopy. Polymer, 36, 1859-1867 (1995). DOI: 10.1016/0032-3861(95)90932-R

[23] Podgórski M.: Structure-property relationship in new photo-cured dimethacrylate-based dental resins. Dental Materials, 28, 398-409 (2012).

DOI: $10.1016 /$ j.dental.2011.11.013

[24] Karger-Kcosis J., Gremmels J.: Use of hygrothermal decomposed polyester-urethane waste for the impact modification of epoxy resins. Journal of Applied Polymer Science, 78, 1139-1151 (2000).

DOI: $10.1002 / 1097-4628(20001031) 78: 5<1139::$ AIDAPP240>3.0.CO;2-Q

[25] Liang Y. L., Pearson R. A.: Toughening mechanisms in epoxy-silica nanocomposites (ESNs). Polymer, 50, 4895-4905 (2009).

DOI: $10.1016 /$ j.polymer.2009.08.014

[26] Liu J., Sue H-J., Thompson Z. J., Bates F. S., Dettloff M., Jacob G., Verghese N., Pham H.: Effect of crosslink density on fracture behavior of model epoxies containing block copolymer nanoparticles. Polymer, 50, 46834689 (2009).

DOI: $10.1016 /$ j.polymer.2009.05.006

[27] Sherman C. L., Zeigler R. C., Verghese N. E., Marks M. J.: Structure-property relationships of controlled epoxy networks with quantified levels of excess epoxy etherification. Polymer, 49, 1164-1172 (2008).

DOI: 10.1016/j.polymer.2008.01.037 